\title{
Effect of surfactant type and droplet size on lipid oxidation in oil-in-water
}

\section{nano-emulsions}

\author{
Ş. Yalçinöz and E. Erçelebi \\ Food Engineering Department, Gaziantep University, Gaziantep-27310, Turkey
}

Corresponding Author: E. Erçelebi, alben@gantep.edu.tr; Ş. Yalçınöz, selalekara@gantep.edu.tr

Received: 15 November 2019 / Accepted: 19 December 2019 / Published: 22 April 2020

(c) 2020 Codon Publications

OPEN ACCESS (C) (i) (2) ()

RESEARCH ARTICLE

\begin{abstract}
The effect of surfactant type and droplet size on the oxidative stability of extra virgin olive oil (EVOO) in bitter orange juice nano-emulsions $[10 \%(\mathrm{w} / \mathrm{w})$ oil phase $](\mathrm{O} / \mathrm{W})$ was investigated. Nano-emulsions stabilised with binary combinations of Tween80, Span20, sucrose monopalmitate (SMP) and sunflower lecithin (SL) were prepared by using phase inversion composition. Thermal oxidation profile of unprocessed EVOO was determined by using the non-isothermal differential scanning calorimetry (DSC) method at five different heating rates over a temperature range of $40-400{ }^{\circ} \mathrm{C}$. Oxidative stability was determined by using the isothermal DSC method at 110, 120, 130 and $140{ }^{\circ} \mathrm{C}$. Temperature dependency of lipid oxidation was shown by using the Arrhenius equation. Droplet size and surfactant type significantly influenced the lipid oxidation. The best oxidative stability was observed in unprocessed EVOO, followed by Tween80/SL nano-emulsion, Tween80/SMP nano-emulsion and Tween80/Span20 nano-emulsion, respectively.
\end{abstract}

Keywords: nano-emulsion, oxidation, stability, surfactant, droplet size

\section{Introduction}

Emulsions and nano-emulsions are thermodynamically unstable systems composed of two immiscible liquids, an oil and an aqueous solution, that can be stabilised kinetically for some time (minutes to years) by the addition of surfactants that are adsorbed at the oil-water interface (Bortnowska, 2015). Emulsions are generally recognised as nano-emulsions when the average droplet diameter is in the range of $20-200 \mathrm{~nm}$ or as high as $500 \mathrm{~nm}$ (Abbas et al., 2013). Nano-emulsions can typically be produced by using high-energy or low-energy approaches. In case of low-energy approaches, a high concentration of surfactant is required to spontaneously emulsify the oil phase (Salvia-Trujillo et al., 2019). Selection of an appropriate surfactant/surfactant blend is crucial in the preparation of nano-emulsions. Non-ionic, small molecule ethoxylated sorbitan esters (Tweens and
Spans) are prevalent in food use since, they are less toxic, non-irritant and well-fitted for both high-energy and low-energy emulsifying methods (McClements and Rao, 2011). Tweens consist of a polyoxyethylene head group and a single hydrocarbon tail (Mahdi et al., 2011). The hydrophobic tail of Tween 80 is curled resulting in maximum curvature and packing parameter to facilitate the preparation of nano-emulsions (Komaiko and McClements, 2016). Span 20 comprise saturated sorbitan lauric acid esters having a cyclic structure with the lowest alkyl chain among the saturated sorbitan monoesters (Korhonen et al., 2002; Sajjadi et al., 2003). In literature, there are several studies using Spans and Tweens individually or as binary combinations (Abbas et al., 2013; Kumar Dey et al., 2012; Peshkovsky et al., 2013; Silva et al., 2012). Lecithin is a lipid mixture with phospholipids which contains two non-polar hydrocarbon chains and a zwitterionic polar head group with positive and 
negative charges derived from amine and phosphate groups, respectively (Chen et al., 2015). Lecithin is also a widely used surfactant in industry due to its low toxicity, biocompatibility and 'generally recognised-as-safe (GRAS)' regulatory status (Chen et al., 2015). Sunflower lecithin (SL) could replace soybean lecithin because of it being a non-GMO product (Cabezas et al., 2016). Nowadays, sugar esters, composed of natural components such as sucrose and vegetable oil, are the favoured surfactants in the food industry based upon their good taste, minor toxicity, improved biodegradability and clean label (Rao and McClements, 2011). SMP is a hydrophilic, water soluble, non-ionic surfactant that has a polar head group (sucrose) and a non-polar tail group (palmitate) (Choi et al., 2011). Many surfactants have better stability and performance when used in combination compared to their individual use in emulsion systems (McClements and Rao, 2011). When used in combinations, the surfactants can form advanced structures on the oil-water interface, and can significantly increase the loading of the oil phase by decreasing interfacial tension (Chen et al., 2015).

The phase inversion composition (PIC) method, which is one of the low-energy emulsification methods, uses chemical energy liberated by the phase transition occurring while the emulsification procedure occurs at a constant temperature (Solans and Solé, 2012). The PIC procedure involves introducing of an aqueous phase into an agitating organic phase. That is, the surfactant and oil constituents that making up the organic phase are uniformly blended together to get a homogeneous solution. The aqueous phase is then titrated into the continuously stirred organic phase at a controlled injection rate (i.e. injection amount per time) (Komaiko and McClements, 2016).

Oxidative stability is a crucial parameter that directly affects quality, stability, shelf-life, consumer acceptance and market value of vegetable oils (Tan and Man, 2002b). The main issue is the oxidation occurring in emulsified foods since emulsification increases the interfacial area at the oil-water interface where the lipid oxidation is initiated (Haahr and Jacobsen, 2008). O/W emulsions have a large surface area and aqueous phase containing prooxidants, antioxidants and an oil-water interface altering the interaction among these components.

Lipid oxidation in $\mathrm{O} / \mathrm{W}$ emulsions show even faster and different mechanisms compared to lipid oxidation in bulk lipids and convectional emulsions (Lee et al., 2010; Waraho et al., 2011). Here are possible scenarios explaining this hypothesis (Lee et al., 2010; Waraho et al., 2011): (1) O/W emulsions have a large surface area due to the small droplet size, (2) they have aqueous phase which may contain pro-oxidants and (3) they may allow more light to penetrate into them because of their weaker light scattering and transparency.

The rate of lipid oxidation in emulsions depends on many factors since it proceeds in a heterogeneous system comprising an oil phase, interfacial layer and aqueous phase (Nakaya et al., 2005; Waraho et al., 2011): oxygen concentration; aqueous phase $\mathrm{pH}$ and ion composition; initial quality characteristics of oil such as fatty acid composition; presence of transition metal ions; type and concentration of pro-oxidative and anti-oxidative compounds; interfacial properties of emulsions such as rheology, thickness, charge and permeability; physical characteristics of emulsion droplets such as droplet size, concentration and physical state and surfactant types.

In the majority of past studies on oxidative stabilities of lipids in emulsion, the emulsions were prepared by employing high energy methods using a rotor-stator homogeniser (Lethuaut et al., 2002), APV Lab 1000 homogeniser (Hu et al., 2003), ultra turrax and table homogeniser (Sørensen et al., 2008), high-pressure valve homogeniser (Osborn and Akoh, 2004), microfluidiser (Walker et al., 2015) and ultra turrax and two-valve Rannie homogeniser (Haahr and Jacobsen, 2008), in which emulsification itself applies undesirable oxidative stress over unsaturated lipids prior to subjecting them to the oxidation process. That is, high-energy methods use mechanical devices that are able to produce the extremely intense disruptive forces to create small droplets, which can be regarded as excess oxidative stress (Lee et al., 2010). In these studies, it is hard to distinguish the cause of the oxidation as that caused by excess oxidative stress or actual oxidation or both of them. There are some limited studies where the emulsions were prepared using low-energy methods such as membrane filtration (Nakaya et al., 2005) and spontaneous emulsification (Walker et al., 2015). An oxidative stress-free technique is crucial to evaluate the oxidative stability of unsaturated oil emulsions (Nakaya et al., 2005).

To the authors' knowledge, so far, there have been numerous papers discussing the oxidative stability of nano-emulsions, namely, lipid oxidation in protein stabilised nano-emulsions evaluated by using the thiobarbituric acid reactive substances (TBARS) method (Lee et al., 2010), lipid oxidation in salmon oil in bulk and nano-emulsions evaluated by using conjugated dienes and infrared spectroscopy (Belhaj et al., 2010) and lipid oxidation in fish oil nano-emulsions evaluated by using the peroxide value and the TBARS method (Walker et al., 2015). However, these conventional chemical methods have major limitations such as being time-consuming and requiring plenty of chemical reagents (Tan and Man, 2002b). Since determination of the exact time when oils reach their peak of 
oxidative degradation is a challenging issue; simple, rapid and reliable methods could be of great assistance (Tan et al., 2002). Therefore, the non-chemical differential scanning calorimetry (DSC) method, as an accelerated oil stability test, is a widely preferred method for the evaluation of oxidative stability of oils and fats (Ostrowska-Ligeza et al., 2010; Tan et al., 2002). The DSC method has been used by several authors (Micić et al., 2015; OstrowskaLigeza et al., 2010; Pardauil et al., 2011; Tan et al., 2002). DSC reports heat flow passing through an oil sample as a function of time or temperature, which is plotted on DSC thermograms, where each peak is associated with a particular physicochemical reaction (Qi et al., 2016). The DSC method is advantageous since it is precise, sensible, requires small samples with minimum preparation, considerably time saving as it produces rapid results and does not use hazardous chemicals (Pardauil et al., 2011; Tan et al., 2001). The DSC method is also useful for obtaining kinetic data for lipid oxidation (Tan and Man, 2002b). Although it is that much useful and applicable; there have been no papers about oxidative stability of nano-emulsions determined by using the DSC method. Data for oxidation kinetics of nano-emulsions are also lacking. As pointed out by Waraho et al. (2011), research in this area is crucial since fastened lipid oxidation due to increased surface of nano-emulsions may complicate the application of this technology in foods.

Olive oil, as an organic phase of the current study, is highly nutritious and beneficial to human health with its unique fatty acid composition, as well as high stability to lipid oxidation. However, finely dispersed olive oil droplets within emulsions have been usually examined for enzymatic reactions and, studies relating finely dispersed oil droplets within real food-grade emulsion systems are lacking (Polychniatou and Tzia, 2014). The bitter orange (Citrus aurantium), whose juice constitutes the aqueous phase of the current study, is a fruit known for its strong natural sour flavour due to the presence of beneficial flavonoids, mostly naringin and neohespiridin, and is also known for its acidity (Peterson et al., 2006). Bitter orange is a well-known citrus fruit produced largely in the Çukurova region of the southern part of Turkey. Due to its sour and bitter taste, it has not been used as an edible fruit. The peel of the fruit is used in jam production and the juice of the fruit is used in salads for imparting a sour taste instead of lemon juice in some regions of Turkey. The use of bitter orange juice in salads can be considered similar to the use of 'Greek salad dressings', which are by definition a mixture of virgin olive oil and lemon juice instantly prepared before use. Bitter orange has recently been the subject of many researches due to its antioxidant activity and total phenolic content, phenolic compounds in the bitter orange peel, effect of elevated atmospheric $\mathrm{CO}_{2}$ on the vitamin $\mathrm{C}$ concentration of sour orange juice, flavonoid content quantification of juice and extraction of bioactive limonin from the sour orange seeds (Erçelebi et al., 2011). Despite increasing demand for bioactive compounds due to potential health benefits, there has been no detailed research and data on the use of bitter orange juice in food systems; especially no studies have been conducted for olive oil-in-bitter orange juice emulsions at the nano-scale.

The goal of the current paper was to evaluate the effect of surfactant type and droplet size on the oxidative stability of extra virgin olive oil (EVOO) in bitter orange juice nano-emulsions. Therefore, a model system, EVOO in bitter orange juice $(10 \%(\mathrm{w} / \mathrm{w})$ oil phase) $(\mathrm{O} / \mathrm{W})$ nano-emulsions, was prepared by using the PIC method. Binary combinations of Tween80, Span20, SMP and SL were used as surfactants. Oxidative stability of nano-emulsions was determined by using the isothermal DSC method and kinetics of lipid oxidation was studied.

\section{Materials and methods}

\section{Materials}

Bitter oranges (Citrus aurantium L.) were harvested at optimum maturity in February 2017, from Mersin, Çukurova region, in Turkey. Polyoxyethylene sorbitan monooleate (Tween 80), Sorbitan monooleate (Span 20) were purchased from Sigma-Aldrich Chemical Company. SMP and SL were gifted by the Compass Foods Company (Singapore). Commercially available Turkish EVOO (Aegeon Region, Erdemit-Ayvalık) was obtained from Tariş Olive and Olive Oil Agricultural Sales Cooperatives Union and used without further purification. Ultrapure water from a Milli-Q Plus system was used for dilution of bitter orange juice concentrates.

\section{Initial quality characteristics of EVOO}

Fatty acid composition (wt \%) was determined in accordance with European Union Commission regulation EEC 2568/91 (EUC, 1991) (corresponding to AOCS method Ch 2-91). Free acidity (\% oleic acid) was determined in accordance with the AOCS Method Ca 5a40. Peroxide value (meq $\mathrm{O}_{2} / \mathrm{kg}$ oil) was determined by using the AOCS Method Cd 8b-90 (AOCS, 1993).

\section{Preparation of nano-emulsions}

Prescreening tests: To define adequate surfactant weight ratios of $S_{A} / S_{B}$ and oil to surfactant mixture ratio $(\mathrm{O} / \mathrm{S}$, where $S$ stand for $S_{A}+S_{B}$ ), nano-emulsions were prepared at many oil-to-surfactant $(\mathrm{O} / \mathrm{S})$ weight ratios by changing surfactant mixture weight ratios. That is, first surfactant mixtures of Tween80/Span20, Tween80/SL and Tween80/ 
SMP were prepared by blending with weight ratios of $\mathrm{S}_{\mathrm{A}} / \mathrm{S}_{\mathrm{B}}=90 / 10,85 / 15,80 / 20,75 / 25$. A certain amount of oil phase, EVOO, was evenly mixed with surfactant mixtures with $\mathrm{O} / \mathrm{S}$ weight ratios of 10/90, 15/85, 20/80 and 25/75 under a stirring rate of $500 \mathrm{rpm}$ via vortex (Velp Scientifica, Europe). These nano-emulsions were observed after 24 h storage at $25{ }^{\circ} \mathrm{C}$ to evaluate visual physical stability (no creaming or phase separation after a one night stand) (data not shown). In the light of prescreening tests, it was decided to study nano-emulsions that comprised 90\% aqueous phase (at $\mathrm{pH} 2.57$, original $\mathrm{pH}$ of aqueous phase), that is, $90 \%$ aqueous phase and $10 \%$ oil phase (surfactant mixture+ olive oil), with binary combinations of Tween80/ Span20, Tween80/SMP and Tween 80/SL with constant oil to surfactant ratio $(\mathrm{O} / \mathrm{S}=15 / 85)$ and surfactant mixing ratio $\left(S_{A} / S_{B}=90 / 10\right)$ due to their high physical stability.

The nano-emulsions prepared in this study could be defined as: bitter orange juice/surfactant mixture $\left(\mathrm{S}_{A}+\mathrm{S}_{B}\right)$ / olive oil (Turkish extra virgin) nano-emulsions at $25{ }^{\mathrm{B}} \mathrm{C}$, which were the nano-emulsions with $90 \%$ aqueous phase (at $\mathrm{pH} 2.57$ ), that is, $90 \%$ aqueous phase and $10 \%$ oil phase (surfactant mixture+ olive oil) with constant oil to surfactant ratio $(\mathrm{O} / \mathrm{S}=15 / 85)$ and surfactant mixing ratio $\left(S_{A} / S_{B}=90 / 10\right)$. The PIC method was used as a low-energy emulsification method. That is, at ambient temperature, first surfactant mixtures of Tween80/Span20, Tween80/ $\mathrm{SL}$ and Tween80/SMP were prepared by blending with a constant weight ratio of $90 / 10\left(S_{A} / S_{B}=90 / 10\right)$. A certain amount of oil phase, EVOO, was evenly mixed with the surfactant mixture with a constant $\mathrm{O} / \mathrm{S}$ weight ratio of $15 / 85(\mathrm{O} / \mathrm{S}=15 / 85)$ under a stirring rate of $500 \mathrm{rpm}$. The final mass of the oil phase was $0.4 \mathrm{~g}$. Bitter orange juice was centrifugated at 5,000 rpm for $60 \mathrm{~min}$ three times, filtered using 20 micron filter paper, which was used as aqueous phase. Finally, a fixed amount of the aqueous phase $(3.6 \mathrm{~g})$ was continuously added to the EVOO and surfactant mixture by a disposable plastic syringe $(5 \mathrm{~mL})$ at an injection rate of $1 \mathrm{~mL} / \mathrm{min}$ and, a stirring rate of 2,400 rpm was maintained in the meantime.

\section{Droplet size determination}

The droplet size distribution (DSD) of the emulsions was measured using a laser light scattering instrument (Partica LA-950, Horiba Ltd., Japan). Droplet size measurements are reported as volume mean diameters $D_{43}\left(D_{43}=\right.$ $\left.\sum n_{\mathrm{i}} d_{\mathrm{i}}^{4} / \sum n_{\mathrm{i}} d_{\mathrm{i}}^{3}\right)$, where $n_{\mathrm{i}}$ is the number of particles with diameter $d i$. The refractive indices of the dispersed and continuous phases used in the calculations of the DSD were 1.135 and 1.330, respectively. To determine the width of the distribution of particle sizes, 'span' was calculated using the following formula:

$$
\text { Span }=(d(v, 90)-d(v, 10)) / d(v, 50)
$$

In this formula, $d(v, 10), d(v, 50)$, and $d(v, 90)$ are diameters at 10,50 , and $90 \%$ cumulative volume, respectively. In other words, $(d(v, 90)-d(v, 10))$ is the range of the data and $d$ $(v, 50)$ is the median diameter (Mahdi Jafari et al., 2006).

\section{Oxidative stability and kinetics of lipid oxidation}

Lipids from nano-emulsions were extracted using a method adopted from Walker et al. (2015). The nano-emulsion $(2 \mathrm{~mL})$ was added to a 3:1 (v/v) mixture of isooctane/2-propanol $(10 \mathrm{~mL})$ and the mixture was vortexed for $30 \mathrm{~s}$, followed by centrifugation at $6,000 \mathrm{rpm}$ for $5 \mathrm{~min}$. The extracted oil was poured into small petri dishes and kept in a dark place for $24 \mathrm{~h}$ to complete volatilisation of organic solvents.

The oxidative stability of nano-emulsions was determined by a PerkinElmer DSC-6 (Norwalk, CT) using a method adopted from Tan et al. (2002). The equipment was calibrated with pure indium and the baseline was obtained by using an empty open aluminium pan. The open aluminium pan was used as the reference. An oil sample of $5.0 \pm 0.5 \mathrm{mg}$ was weighed in the open aluminium pan and placed in the sample chamber. To generate the oxidative profile (heat flow against temperature), the system was equilibrated at $40^{\circ} \mathrm{C}$ for $5 \mathrm{~min}$ and then heated linearly to $400{ }^{\circ} \mathrm{C}$ at $5,7,10,12$, and $15^{\circ} \mathrm{C} / \mathrm{min}$ with oxygen gas flowing at a rate of $50 \mathrm{~mL} / \mathrm{min}$ as shown in Figure 1 . Oxidation onset temperature $\left(T_{\text {on }}\right)$, maximum heat flow temperature $\left(T_{\mathrm{p}}\right)$, oxidation offset temperature $\left(T_{\text {off }}\right)$ and enthalpy $(\Delta H)$ at each heating rate were calculated by the help of software provided by the manufacturer. $T$ on that is closely associated with the formation of peroxides is the temperature at which a rapid increase occurs in heat flow, which was calculated by extrapolating the tangent drawn on the steepest slope of the DSC (Qi et al., 2016).

Isothermal temperature was programmed at 110,120 , 130 and $140{ }^{\circ} \mathrm{C}$, and purified oxygen (99.8\%) was passed through the sample enclosure at $50 \mathrm{~mL} / \mathrm{min}$. Induction time $\left(T_{0}\right)$, which is the time before a dramatic increase in the rate of lipid oxidation, is taken as an indicator to evaluate the relative stability of oil toward oxidation (Tan et al., 2002). $T_{\mathrm{o}}$ of the oxidation reaction was found by the help of software.

A kinetic rate constant was taken as the inverse of the oxidative induction time $\left(T_{\mathrm{o}}\right)\left(k=1 / T_{\mathrm{o}}, \mathrm{min}^{-1}\right)$. Arrhenius equation is used to express temperature dependency of lipid oxidation (Equation 1):

$$
\ln (k)=\ln A-E_{\mathrm{a}} / R T
$$

where $k$ is the reaction rate constant or reciprocal $T_{\mathrm{o}}, A$ is the pre-exponential factor or frequency factor, $E_{\mathrm{a}}$ is the 


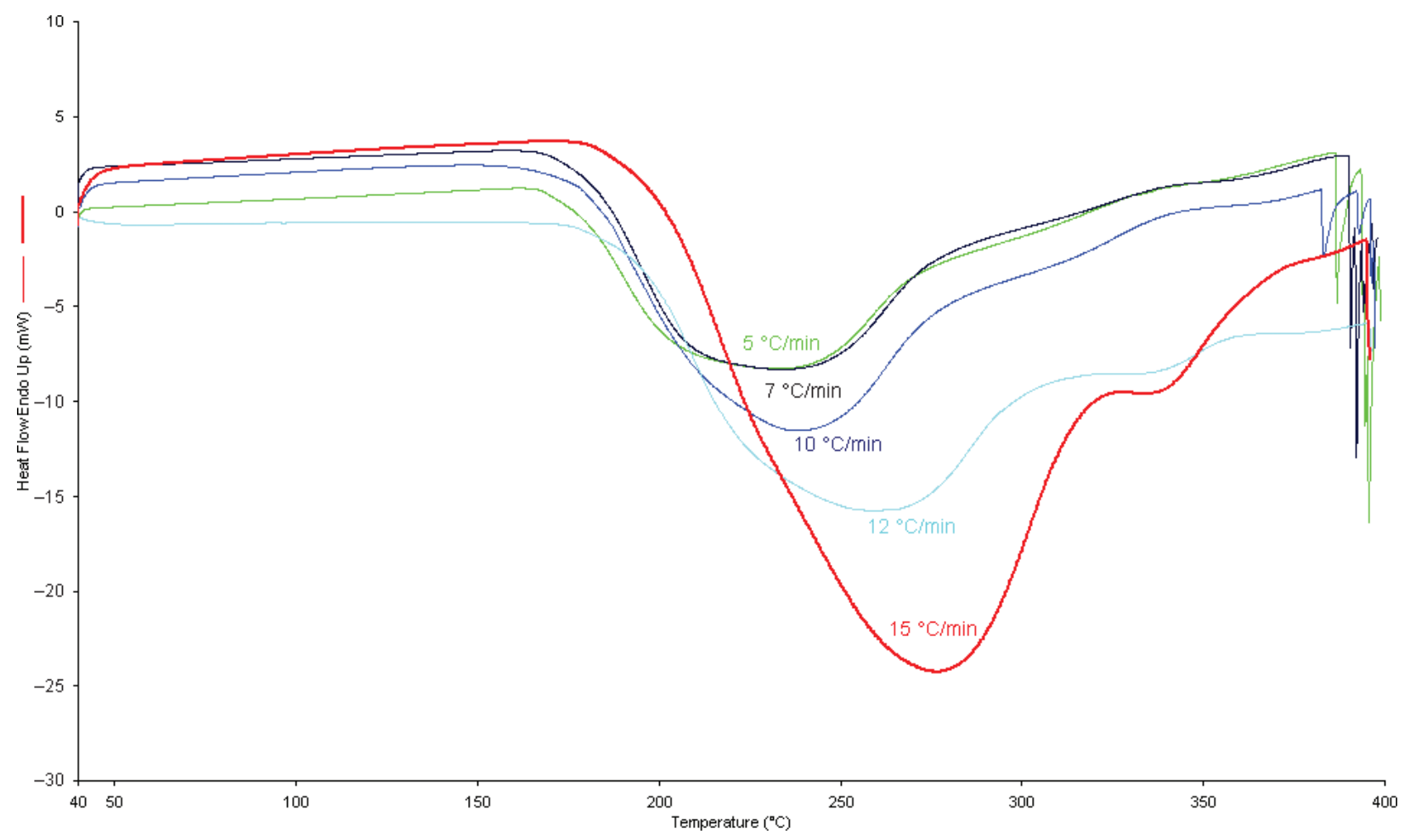

Figure 1. DSC oxidative profiles of EVOO at different heating rates $\left(5,7,10,12\right.$ and $\left.15^{\circ} \mathrm{C} / \mathrm{min}\right)$.

activation energy $(\mathrm{kJ} / \mathrm{mol}), R$ is the molar gas constant $(8.314510 \mathrm{~J} / \mathrm{mol} \cdot \mathrm{K})$ and $T$ is the absolute temperature (K). $E_{\mathrm{a}}$ and $A$ were determined from the slopes and intercepts, respectively. The $E$ was computed from Equation (1), using a linear regression procedure of the SigmaPlot (SigmaPlot 10.0 Windows version, SPSS Inc.).

\section{Statistical analyses}

All measurements were performed duplicate and the results were reported as means and standard deviations. Experimental data were subjected to ANOVA and the means were compared by using Tukey's multiple range test at $P<0.05$ significance level using SPSS version 22 (SPSS Inc., Chicago, IL, USA). Pearson's correlation test was used to determine point-biserial correlation among emulsion type, droplet size and oxidative stability.

\section{Results and discussion}

\section{Initial quality characteristics of EVOO}

Initial characteristics of the EVOO are given in Table 1. The per cent distributions of fatty acids in the composition (Table 1) are found in the normal range expected for the olive oil (IOOC, 2013). Free acidity ( $\leq 0.8 \%$ oleic acid)
Table 1. Initial quality characteristics of EVOO.

\begin{tabular}{|c|c|}
\hline Fatty acid composition (\%) & \\
\hline $\mathrm{C} 14: 0$ & 0.02 \\
\hline C16:0 & 13.69 \\
\hline C17:0 & 0.15 \\
\hline $\mathrm{C} 18: 0$ & 2.70 \\
\hline $\mathrm{C} 20: 0$ & 0.43 \\
\hline $\mathrm{C} 22: 0$ & 0.16 \\
\hline$\Sigma S F A$ & 17.15 \\
\hline C16:1 & 0.91 \\
\hline C17:1 & 0.23 \\
\hline C18:1 & 68.84 \\
\hline C20:1 & 0.29 \\
\hline $\mathrm{C} 22: 1$ & 0.09 \\
\hline$\Sigma M U F A$ & 70.36 \\
\hline C18:2 & 11.82 \\
\hline C18:3 & 0.67 \\
\hline$\Sigma$ PUFA & 12.49 \\
\hline MUFA/PUFA & 5.63 \\
\hline Peroxide value (meq $\mathrm{O}_{2} / \mathrm{kg}$ oil) & 6.53 \\
\hline Free fatty acid (\%, oleic acid) & 0.68 \\
\hline
\end{tabular}


and peroxide value ( $\leq 20$ meq $\mathrm{O}_{2} / \mathrm{kg}$ oil) (Table 1 ) indicated that the oil used in the current study could be defined as first-class as stated by IOOC (2013) and it was unoxidised before the emulsification.

Beltrán et al. (2004) reported that autoxidation depends on the chemical structure and degree of unsaturation of the fatty acid, and in virgin olive oils, the MUFA/PUFA or oleic/linoleic ratios are responsible for oxidative stability as well as the natural antioxidant content. The MUFA/ PUFA ratio was 5.63 for EVOO presented in the current study, which can be an indicator of good oxidative stability since higher levels of ratio signify greater oxidative stability (Farhoosh and Hoseini-Yazdi, 2014).

\section{Oxidative stability by DSC}

Representative DSC oxidation profile of EVOO at different heating rates was shown in Figure 1. Figure 1 shows that the oxidation process continued as three distinct steps showing different trends regardless of differences in the heating rates. That is, between 150 and $210{ }^{\circ} \mathrm{C}$ the first clear exothermic peak was noted, between 210 and $380{ }^{\circ} \mathrm{C}$ the longest smooth parabolic peak was noted and over $380^{\circ} \mathrm{C}$ complicated fluctuations were observed. This oxidation trend fits the thermal oxidative degradation theory for olive oil proposed by Lazzari and Chiantore (1999), which states that between 150 and $250^{\circ} \mathrm{C}$ exothermic process is probably associated with the oxidation of unsaturated fatty acids; between 250 and $400{ }^{\circ} \mathrm{C}$, the initial step of oxidative decomposition is noted and beyond $400{ }^{\circ} \mathrm{C}$ the main progress of decomposition (combustion) occurs which brings complete volatilisation. Rudnik et al. (2001) in their study of oxidative stability evaluation of linseed oil observed a first clear exothermic peak, related to oxidation of unsaturated fatty acids between 150 and $320^{\circ} \mathrm{C}$. It can be concluded that as the type of the oil changes oxidation profile changes, but for the same type of oil oxidation profile shape does not change with the change of heating rates, only shape shifts towards higher temperatures. As shown in Figure 1, it was clearly observed that oxidation profiles of EVOOs were of similar shape. At heating rates of 5 and
$7{ }^{\circ} \mathrm{C} / \mathrm{min}$, EVOOs showed nearly the same trend; as heating rate increased further, the oxidation profile shifted against the temperature. Adhvaryu et al. (2000) and Micić et al. (2015) proposed a possible theory that during gentle heating, initial oxidation products (e.g. hydroperoxides) cannot escape from the oil phase by evaporation. In contrast, by reacting with excess oxygen and oil molecules, they form intermediate oxidation products (e.g. aldehydes, acids) that will continue to remain in the oil phase, which promote degradation. At higher heating rates, the primary oxidation products rapidly passed towards a gaseous phase by evaporation prior to undergoing further decomposition in the oil phase, due to which $T_{\text {on }}$ was generally postponed and initiated at a much higher temperature. That is, as the heating rate increases, the $T_{\text {on }}$ increases. These results were in agreement with previous studies (Adhvaryu et al., 2000; Micić et al., 2015; Ostrowska-Ligeza et al., 2010; Qi et al., 2016). $T_{\mathrm{p}}$ and $T_{\text {off }}$ values also showed a similar shift.

Table 2 shows $T_{\text {on }}, T_{\mathrm{p}}, T_{\text {off }}$ and $\Delta H$ values of EVOO. $T_{\text {on }}$ is the most suitable parameter to evaluate lipid oxidation under non-isothermal conditions (Qi et al., 2016) and can be taken as a primary indicator for resistance of an oil to the thermal oxidation (Ostrowska-Ligeza et al., 2010). $T_{\mathrm{p}}$, which is indicative of the termination stage, is a maximum point where the heat flow has reached on the DSC thermogram (Qi et al., 2016). $T_{\text {off }}$ is the point where the extrapolated leading edge of the last endotherm intersected with the baseline (Tan and Man, 2002a). $\mathrm{T}_{\text {on }}, T_{\mathrm{p}}, T_{\text {off }}$ and $\Delta H$ values of EVOO ranged between 179.24 and $-201.57^{\circ} \mathrm{C}$, 219.07 and $271.20{ }^{\circ} \mathrm{C}, 270.33$ and $315.93{ }^{\circ} \mathrm{C}$ and -1.576 and $-1.620 \mathrm{~kJ} / \mathrm{mol}$, respectively. Qi et al. (2016) reported that between the heating ranges of 5 and $15^{\circ} \mathrm{C} / \mathrm{min}, T_{\text {on }}$ and $T$ values range between $187.3-208.6{ }^{\circ} \mathrm{C}$ and $253.1^{\text {on }}$ $299.7{ }^{8} \mathrm{C}$, respectively for olive oil. Ostrowska-Ligeza et al. (2010) studied oxidation kinetics of four different commercial olive oils by DSC and reported $T_{\text {on }}$ values ranging from 159.8 to $183.8^{\circ} \mathrm{C}$. These results were in reasonable agreement with our measurements.

DSC oxidative induction times $\left(T_{\mathrm{o}}\right)$ was given in Table $3 . T_{\mathrm{o}}$ values of unprocessed EVOO at $110,120,130$ and $140^{\circ} \mathrm{C}$

Table 2. Oxidation onset temperature $\left(T_{\text {on }}\right)$, maximum heat flow temperature $\left(T_{p}\right)$, oxidation offset temperature $\left(T_{\text {off }}\right)$ and enthalpy $(\Delta H)$ of EVOO under the five heating rates.

\begin{tabular}{lcccc} 
Heating rate $\left({ }^{\circ} \mathrm{C} / \mathrm{min}\right)$ & $\boldsymbol{T}_{\text {on }} \pm \mathrm{SD}\left({ }^{\circ} \mathrm{C}\right)$ & $\boldsymbol{T}_{\mathrm{p}} \pm \mathrm{SD}\left({ }^{\circ} \mathrm{C}\right)$ & $\boldsymbol{T}_{\text {off }} \pm \mathrm{SD}\left({ }^{\circ} \mathrm{C}\right)$ & $\Delta H \pm \mathrm{SD}(\mathrm{kJ} / \mathrm{mol})$ \\
\hline 5 & $179.24 \pm 12.67$ & $219.07 \pm 15.49$ & $270.33 \pm 19.12$ & $-1.576 \pm 0.11$ \\
7 & $182.04 \pm 12.87$ & $216.32 \pm 15.30$ & $272.74 \pm 19.29$ & $-1.311 \pm 0.09$ \\
10 & $184.36 \pm 13.04$ & $232.56 \pm 16.44$ & $272.78 \pm 19.32$ & $-1.387 \pm 0.10$ \\
12 & $197.86 \pm 13.99$ & $246.49 \pm 17.43$ & $294.28 \pm 20.81$ & $-1.010 \pm 0.07$ \\
15 & $201.57 \pm 14.25$ & $271.20 \pm 19.18$ & $315.93 \pm 22.34$ & $-1.620 \pm 0.11$ \\
\hline
\end{tabular}

EVOO, extra virgin olive oil. 
were $168.477,98.404,34.630$ and $18.452 \mathrm{~min}$, respectively. It was clearly observed that as the isothermal temperature increased, $T_{\mathrm{o}}$ values decreased. Moreover, generally for each increase by $10^{\circ} \mathrm{C}$, the $T$ value was found to be half of its previous reading, which was in agreement with studies of Tan et al. (2002). In their study, $T$ of olive oil at 110 , 120,130 and $140{ }^{\circ} \mathrm{C}$ were reported as $169.02,51.00,21.99$ and $13.94 \mathrm{~min}$, respectively. These results were in accordance with our findings. Small differences among the results could be attributed to their various compositions. $T$ of oils extracted from Tween80/SL, Tween80/SMP and Tween80/Span20 nano-emulsion at 110, 120, 130 and $140{ }^{\circ} \mathrm{C}$ were given in Table 3 . Temperature significantly affected $T_{\mathrm{o}}(P<0.05)$ values. A weak negative relation was found between temperature and oxidative induction time, $T_{\mathrm{o}}$, according to the Pearson's test $(r=-0.339 ; P<0.01)$. In general, $T$ values of oil extracted from nano-emulsions were lower than $T_{0}$ values of unprocessed olive oil. For oil extracted from Tween80/SL nano-emulsion, as temperature increased from 110 to $140{ }^{\circ} \mathrm{C}, T_{\mathrm{o}}$ decreased from 106.184 to $20.246 \mathrm{~min}$. No definite trend was observed in $T_{\mathrm{o}}$ values of oil extracted from Tween80/SMP and Tween80/Span20 nano-emulsion, which were relatively low as compared to $T_{0}$ values of oil extracted from Tween80/SL nano-emulsions.

\section{Kinetics of lipid oxidation}

The reaction rate constant $(k)$ values of lipid oxidation of oils extracted from Tween80/SL, Tween80/SMP and Tween80/Span20 nano-emulsion and unprocessed EVOO at $110,120,130$ and $140{ }^{\circ} \mathrm{C}$ were given in Table 4. Temperature significantly $(P<0.05)$ affected $k$ of lipid oxidation in nano-emulsions. Tan et al. (2001) proposed that only $k$ is temperature dependent since concentration remains constant or almost unchanged as the temperature changes, providing that $k$ directly expresses the influence of temperature on the lipid oxidation rate. In general, $k$ values of oil extracted from nano-emulsions were higher than $k$ values of unprocessed olive oil, which shows that extracted oils from nano-emulsions were more prone to oxidation than unprocessed EVOO. There was pronounced increase in the rate of lipid oxidation $(k)$ as temperature increases from 110 to $140{ }^{\circ} \mathrm{C}$ for unprocessed EVOO and for oils extracted from the Tween80/ SL nano-emulsion. As temperature increases from 110 to $140{ }^{\circ} \mathrm{C}$, a slight increase was observed in $k$ values of oil extracted from Tween80/SMP and Tween80/Span20 nano-emulsion, which were relatively high as compared to $k$ values of oil extracted from Tween80/SL nano-emulsions. This result was in accordance with $T_{\mathrm{o}}$ values. Ostrowska-Ligeza et al. (2010) reported $k$ values for oil oxidation for four different olive oil samples. Farhoosh et al. (2008) analysed oil oxidation of many vegetable oils under Rancimat conditions at different temperature ranges and, reported that $k$ values of olive oil oxidation at 100, 110, 120 and $130{ }^{\circ} \mathrm{C}$ were $0.0045,0.0089,0.1772$ and $0.3620 \mathrm{~min}^{-1}$ respectively. Their results cover our findings ranging between 0.0059 and $0.0542 \mathrm{~min}^{-1}$. Small differences among the results could be attributed to variation in composition of oil samples and experimental conditions.

Table 3. DSC oxidative induction time, $T_{0}$.

\begin{tabular}{lccrc} 
& \multicolumn{4}{c}{ Oxidative induction time, $T_{0} \pm \mathrm{SD}$ (min) } \\
\cline { 2 - 5 } & $110^{\circ} \mathrm{C}$ & $120^{\circ} \mathrm{C}$ & \multicolumn{1}{c}{$130^{\circ} \mathrm{C}$} & $140{ }^{\circ} \mathrm{C}$ \\
\hline EVOO (unprocessed) & $168.477 \pm 11.91$ & $98.404 \pm 6.96$ & $34.630 \pm 2.45$ & $18.452 \pm 1.30$ \\
Tween80/SL nano-emulsion & $106.184 \pm 7.51$ & $64.349 \pm 4.55$ & $30.490 \pm 2.16$ & $20.246 \pm 1.43$ \\
Tween80/SMP nano-emulsion & $1.572 \pm 0.10$ & $1.571 \pm 0.11$ & $1.545 \pm 0.12$ & $1.530 \pm 0.11$ \\
Tween80/Span20 nano-emulsion & $1.123 \pm 0.08$ & $1.116 \pm 0.06$ & $1.114 \pm 0.03$ & $1.113 \pm 0.08$ \\
\hline
\end{tabular}

EVOO, extra virgin olive oil; SMP, sucrose monopalmitate; SL, sunflower lecithin.

Table 4. The reaction rate constants $(k)$ at four different temperatures $(T)$ for DSC oxidative stability measurements.

\begin{tabular}{lcccc} 
Olive oil source & \multicolumn{4}{c}{ Reaction rate constants, $\boldsymbol{k} \pm \mathbf{S D}\left(\mathrm{min}^{-1}\right)$} \\
\cline { 2 - 5 } & $110^{\circ} \mathrm{C}$ & $120^{\circ} \mathrm{C}$ & $130^{\circ} \mathrm{C}$ & $140{ }^{\circ} \mathrm{C}$ \\
\hline EVOO (unprocessed) & $0.0059 \pm 0.00$ & $0.0102 \pm 0.00$ & $0.0289 \pm 0.00$ & $0.0542 \pm 0.00$ \\
Tween80/SL nano-emulsion & $0.0094 \pm 0.00$ & $0.0155 \pm 0.00$ & $0.0328 \pm 0.00$ & $0.0494 \pm 0.00$ \\
Tween80/SMP nano-emulsion & $0.6361 \pm 0.05$ & $0.6365 \pm 0.05$ & $0.6472 \pm 0.04$ & $0.6536 \pm 0.05$ \\
Tween80/Span20 nano-emulsion & $0.8905 \pm 0.06$ & $0.8961 \pm 0.06$ & $0.8977 \pm 0.06$ & $0.8985 \pm 0.06$ \\
\hline
\end{tabular}

EVOO, extra virgin olive oil; SMP, sucrose monopalmitate; SL, sunflower lecithin. 
Table 5. Estimated Arrhenius Equations $\left(\operatorname{lnk}=\ln A-E_{a} / R T\right)$ for lipid oxidation of EVOO.

\begin{tabular}{lccc} 
Olive oil source & Regression Equation & $\boldsymbol{E}_{\mathrm{a}}(\mathbf{k J} / \mathrm{mol})$ & Coefficient of determination $\left(\boldsymbol{R}^{2}\right)$ \\
\hline EVOO (unprocessed) & $y=26.4688-12134.4918 x$ & 100.89 & 0.9833 \\
Tween80/SL nano-emulsion & $y=18.9406-9049.0663 x$ & 75.23 & 0.9895 \\
Tween80/SMP nano-emulsion & $y=-0.0536-154.1095 x$ & 1.28 & 0.9013 \\
Tween80/Span20 nano-emulsion & $y=0.0047-45.6933 x$ & 0.38 & 0.8556 \\
\hline
\end{tabular}

EVOO, extra virgin olive oil; SMP, sucrose monopalmitate; SL, sunflower lecithin; DSC, differential scanning calorimetry.

Table 5 provides the reaction rate constant and temperature relationship that was estimated by Arrhenius Equations (In $\left.k=\operatorname{In} A-E_{a} / \mathrm{RT}\right)$ [Eq. (1)] and activation energy $\left(E_{\mathrm{a}}\right)$ for lipid oxidation of EVOOs. The high coefficient of determination, $\left(R^{2}>0.8556\right)$ indicates that experimental data showed good fit to the Arrhenius Equation. $E$ of unprocessed EVOO, oils extracted from Tween80/ SL, Tween $80 / S M P$ and Tween $80 /$ Span 20 nano-emulsions were $100.89,75.23,1.28$ and $0.38 \mathrm{~kJ} / \mathrm{mol}$, respectively. The low activation energy value points to a higher reaction rate, while the high activation energy value points to a deferred degradation rate (Ahmed et al., 2000). According to $E_{\text {a }}$ values, the oxidative stability of unprocessed EVOO was higher than that of the other oils extracted from nano-emulsions. Ostrowska-Ligeza et al. (2010) reported $E$ values for oil oxidation of four different olive oil samples ranges between 72.0 and $104.3 \mathrm{~kJ} / \mathrm{mol}$ at a temperature range of $100-170{ }^{\circ} \mathrm{C}$. Farhoosh et al. (2008) reported the $E$ of olive oil oxidation studied at temperature range $100^{\mathrm{a}}-130{ }^{\circ} \mathrm{C}$ was $86.86 \mathrm{~kJ} / \mathrm{mol}$. These results were in reasonable agreement with $E_{\mathrm{a}}$ of unprocessed EVOO presented in the current study ${ }^{2}(100.89 \mathrm{~kJ} / \mathrm{mol})$. Unfortunately, there has been no data related to oxidation kinetics of nano-emulsions in the literature.

Under the light of DSC analyses and oxidation kinetics, oxidative stability of the nano-emulsion decreased in the order as Tween80/SL nano-emulsion > Tween80/ SMP nano-emulsion $>$ Tween $80 /$ Span20 nano-emulsion. Since the emulsion system has complex stereochemistry, several factors such as droplet sizes, surfactant type etc. could be attributed solely or in with combination to differences in oxidative stability.

\section{Effect of droplet size and surfactant type on oxidative stability}

Droplet size scale for the analysed nano-emulsions could be ranked as Tween80/SL nano-emulsion $\left(D_{43}=569 \pm\right.$ $40.23 \mathrm{~nm})>$ Tween80/SMP nano-emulsion $\left(D_{43}=348 \pm\right.$ $24.60 \mathrm{~nm})>$ Tween $80 / \operatorname{Span} 20\left(D_{43}=143 \pm 10.13 \mathrm{~nm}\right)$ nano-emulsion. Span values of Tween80/SL nano-emulsion, Tween80/SMP nano-emulsion and Tween80/Span20 nano-emulsion were $1.34,0.92$ and 0.93 , respectively.
The smaller the span value, the narrower the particle size distribution (Lovelyn and Attama, 2011). DSDs of nano-emulsion prepared with Tween 80/Span20 and Tween80/ SMP were unimodal with one peak and, Tween80/SL nano-emulsion showed bimodal size distribution with two peaks (Figure 2). A strong negative relation was found between surfactant type and droplet size according to the Pearson's test $(r=-1.000 ; P<0.01)$.

Haahr and Jacobsen (2008) suggested that emulsion droplets covered by lecithin often had bigger size than the ones covered by Tween 80 , Citrem or sodium caseinate, irrespective of $\mathrm{pH}$ and addition of $\mathrm{Fe}^{+2} . T_{\mathrm{o}}$ of oils extracted from Tween80/SL, Tween80/SMP and Tween80/Span 20 nano-emulsion between 110 and $140{ }^{\circ} \mathrm{C}$ ranged from 106.184-20.246, $1.572-1.530$ and 1.123-1.113 min, respectively (Table 3 ). Droplet size effect on $T$ was significantly $(P<0.05)$ similar in Tween80/SMP and Tween 80/Span20 nano-emulsion, which was different from Tween 80/SL nano-emulsions. A significant negative correlation was found between surfactant type and oxidative induction time, $T_{0}$, according to the Pearson's test $(r=-0.690 ; P<0.01)$. Pearson's test showed a significant positive correlation between droplet size and $T$. $(r=0.699 ; P<0.01)$. There were statistically significant $(P<$ 0.05 ) differences among the effect of droplet size on $k$ of nano-emulsions. A strong negative correlation was found between droplet size and $k(r=-0.973 ; P<0.01)$. A strong positive correlation was found between surfactant type and $k(r=0.968 ; P<0.01)$. As the droplet size decreased, oxidation proceeded in faster rates (high $k$ values) in shorter induction times (low $T_{\mathrm{o}}$ values). Under constant oil concentrations, surface area of the droplets increases as the droplet diameter decreases (Nakaya et al., 2005). Oxidation rate is expected to rise due to the increase in surface area of droplets, which is exposed to the aqueous phase (McClements and Decker, 2000), which explains the decreased oxidative stability along with decreased droplet size of nano-emulsions in the current study. Lethuaut et al. (2002) reported that in a situation where oxygen concentration was in excess, increasing the surface area of emulsions increased lipid oxidation in bovine serum albumin-stabilised sunflower oil (O/W) emulsions which supports our findings. In their study of oxidation of 


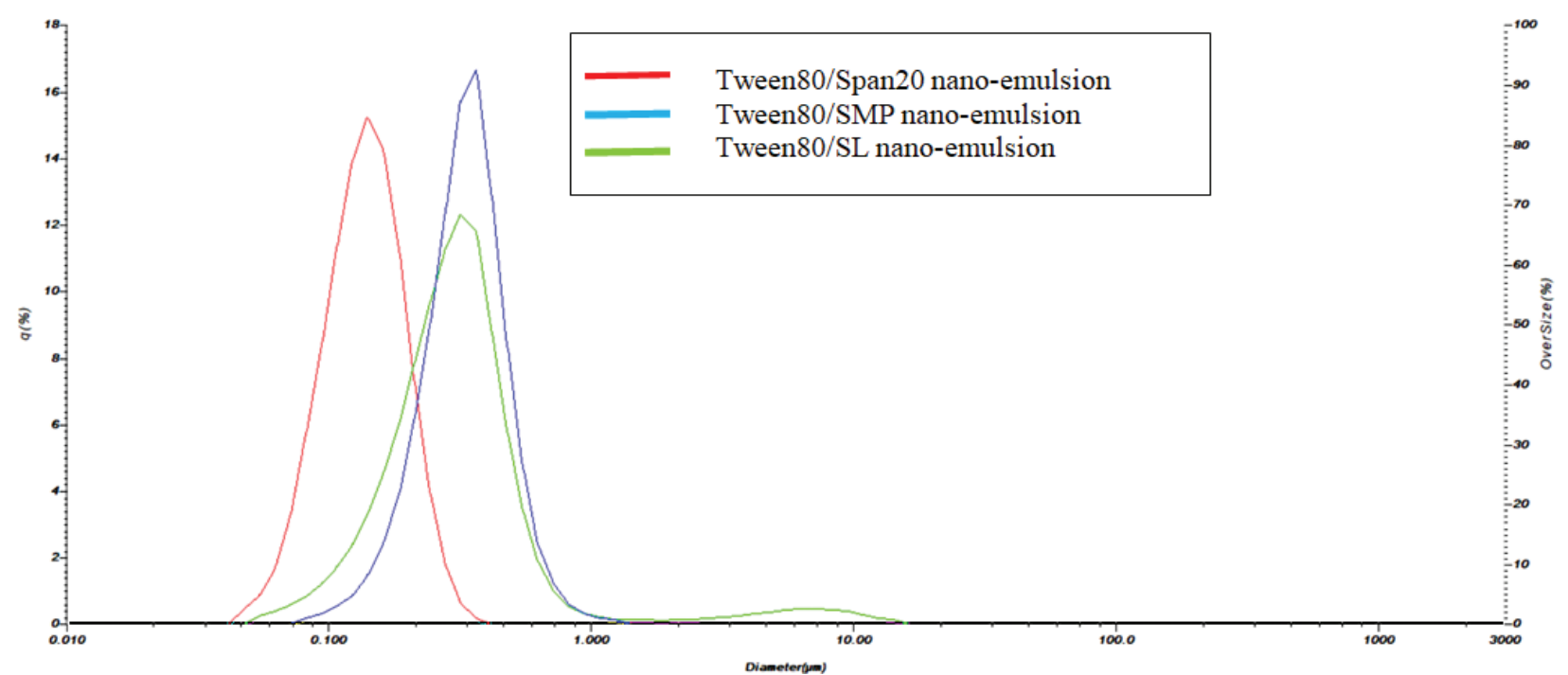

Figure 2. Droplet size distribution graph of olive oil-in-bitter orange juice nano-emulsions prepared with Tween80/Span20, Tween80/SMP and Tween80/SL with constant oil to surfactant ratio $(O / S=15 / 85)$ and surfactant mixing ratio $\left(S_{A} / S_{B}=90 / 10\right)$.

fish O/W emulsions, Haahr and Jacobsen (2008) observed rapid oxidation in small droplets and drew attention to this result that could also be attributed to differential emulsifier types. Walker et al. (2015) observed that in the fish oil emulsions, neither droplet size nor surfactant concentration had a significant influence on lipid oxidation rate. In the study of influence of droplet size on the oxidative stability of polyunsaturated triacylglycerols in $\mathrm{O} / \mathrm{W}$ emulsions, Nakaya et al. (2005) reported that oxidative stability strengthened as droplet size decreased. Osborn and Akoh (2004) reported that emulsion droplet size did not influence oxidative stability in caprylic acid/canola oil $(\mathrm{O} / \mathrm{W})$ emulsion. In addition, previous researchers reported that droplet size was not the main parameter that altered oxidative stability compared to emulsifier type (Hu et al., 2003; Sørensen et al., 2008). There is no consistency among previous studies. As mentioned before, in most of these studies emulsions were produced via high-energy methods, that is, the main cause of the oxidation is ambiguous which was a result of excess oxidative stress or actual oxidation or both of them. Further investigations are needed related to this phenomenon.

Surfactants influence many properties of an emulsion such as droplet charge, interfacial layer thickness and permeability, which in turn influence accessibility of pro-oxidants, free radicals and oxygen to droplets (Walker et al., 2015). Statistical analyses revealed that surfactant type significantly $(P<0.05)$ affected the oxidative stability of nano-emulsions. In the current study, all nano-emulsions contained equal amounts of Tween 80 , so it was assumed that Tween 80 has the same effect on all nano-emulsions regardless of differences in co-surfactant type. Differences in oxidative stability of related emulsions were solely attributed to differences in Span 20, SMP and SL.

Oxidative stability in $\mathrm{O} / \mathrm{W}$ emulsions also depends on the electrostatic interaction between droplets and cationic metals. Final droplet charge is determined by surfactant properties, other ionic components and $\mathrm{pH}$ of the emulsion. Droplets surrounded by anionic surfactants have a negative charge, whereas those surrounded by cationic surfactants have a positive charge (McClements, 2011). Emulsion droplets surrounded by anionic surfactants speed up oxidation by electrostatically attracting cationic metals, while particles surrounded by cationic surfactants retard oxidation rates by electrostatically repelling metals (Waraho et al., 2011). Theoretically, droplets surrounded by non-ionic surfactants should be uncharged, actually they possess considerable negative charge (McClements, 2011). For instance, Rao and McClements (2011) revealed that even SMP is a non-ionic surfactant, droplets possess low negative charge under $\mathrm{pH}$. However, it is assumed that the electric charge of the non-ionic surfactant is too low to affect the lipid oxidation significantly (Walker et al., 2015). In the current study, Tween 80, Span 20 and SMP are non-ionic surfactants and droplets coated with those surfactants had minimal negative particle charge, whose effect on lipid oxidation can be neglected. In theory, lecithin forms negatively charged layers on the oil droplets under acidic conditions (Bortnowska, 2015) and is expected to oxidise rapidly (Waraho et al., 2011). However, experimental results showed that nanoemulsion stabilised with Tween80/SL showed the highest oxidative stability. Haahr and Jacobsen (2008), in their study on factors effecting oxidative stability of oil-in-water 
emulsion, found that lecithin emulsions showed good oxidative stability as compared to Tween and Citrem emulsions, which was attributed to the anti-oxidative effect of lecithin itself due to its being a metal chelate. Our findings could support this hypothesis.

\section{Conclusions}

In the light of DSC analyses, oxidation kinetics and statistical analyses, the best oxidative stability was observed in unprocessed EVOO and followed by oils extracted from Tween80/SL nano-emulsion, Tween80/SMP nanoemulsion and Tween80/Span20 nano-emulsion. Droplet size and surfactant type significantly influenced the lipid oxidation in nano-emulsions. As the droplet size decreased, the surface area increased resulting in oxidation in faster rates (high $k$ values) in shorter induction times (low $\mathrm{T}_{0}$ values). Nano-emulsion stabilised with Tween80/ SL showed the highest oxidative stability which may attributed to the anti-oxidative effect of lecithin itself due to its being a metal chelate.

\section{References}

Abbas, S., Hayat, K., Karangwa, E., Bashari, M. and Zhang, X., 2013. An overview of ultrasound-assisted food-grade nanoemulsions. Food Engineering Reviews 5: 139-157. https://doi.org/10.1007/ s12393-013-9066-3

Adhvaryu, A., Erhan, S., Liu, Z. and Perez, J., 2000. Oxidation kinetic studies of oils derived from unmodified and genetically modified vegetables using pressurized differential scanning calorimetry and nuclear magnetic resonance spectroscopy. Thermochimica Acta 364: 87-97.

Ahmed, J., Shivhare, U. and Raghavan, G., 2000. Rheological characteristics and kinetics of colour degradation of green chilli puree. Journal of Food Engineering 44: 239-244.

AOCS, 1993. Official methods and recommended practices of the American Oil Chemists' Society (Method Ca 5a-40 and Method Cd 8b-90). AOCS press, Champaign, IL.

Belhaj, N., Arab-Tehrany, E. and Linder, M., 2010. Oxidative kinetics of salmon oil in bulk and in nanoemulsion stabilized by marine lecithin. Process Biochemistry 45: 187-195.

Beltrán, G., del Rio, C., Sánchez, S. and Martínez, L., 2004. Influence of harvest date and crop yield on the fatty acid composition of virgin olive oils from cv. Picual. Journal of Agricultural and Food Chemistry 52: 3434-3440.

Bortnowska, G., 2015. Multilayer oil-in-water emulsions: formation, characteristics and application as the carriers for lipophilic bioactive food components-a review. Polish Journal of Food and Nutrition Sciences 65: 157-166.

Cabezas, D.M., Diehl, B.W. and Tomás, M.C., 2016. Emulsifying properties of hydrolysed and low HLB sunflower lecithin mixtures. European Journal of Lipid Science and Technology 118: 975-983.
Chen, H., Guan, Y. and Zhong, Q., 2015. Microemulsions based on a sunflower lecithin-Tween 20 blend have high capacity for dissolving peppermint oil and stabilizing coenzyme Q10. Journal of Agricultural and Food Chemistry 63: 983-989.

Choi, S.J., Decker, E.A., Henson, L., Popplewell, L.M., Xiao, H. and McClements, D.J., 2011. Formulation and properties of model beverage emulsions stabilized by sucrose monopalmitate: Influence of $\mathrm{pH}$ and lyso-lecithin addition. Food Research International 44: 3006-3012. https://doi.org/10.1016/j.foodres.2011.07.007

Erçelebi, E., Kara, S. and Ibanoglu, E., 2011. Stability of bitter orange juice-olive oil salad dressings stabilized with polysaccharides. Journal of Food Science and Engineering 1: 297.

EUC, 1991. European Union Commission Regulation EEC/2568/91 on the characteristics of olive and olive pomace oils and their analytical methods. Official Journal of the European Communities L 248: 1991.

Farhoosh, R. and Hoseini-Yazdi, S.-Z., 2014. Evolution of oxidative values during kinetic studies on olive oil oxidation in the Rancimat test. Journal of the American Oil Chemists' Society 91: 281-293.

Farhoosh, R., Niazmand, R., Rezaei, M. and Sarabi, M., 2008. Kinetic parameter determination of vegetable oil oxidation under Rancimat test conditions. European Journal of Lipid Science and Technology 110: 587-592.

Haahr, A.M. and Jacobsen, C., 2008. Emulsifier type, metal chelation and $\mathrm{pH}$ affect oxidative stability of $\mathrm{n}$-3-enriched emulsions. European Journal of Lipid Science and Technology 110: 949-961.

Hu, M., McClements, D.J. and Decker, E.A., 2003. Lipid oxidation in corn oil-in-water emulsions stabilized by casein, whey protein isolate, and soy protein isolate. Journal of Agricultural and Food Chemistry 51: 1696-1700.

IOOC, 2013. International Olive Oil Council. Trade standard applying to olive oil and olive-pomace oil. COI/T. 15/NC No 3/Rev. 7, Madrid May 2013.

Korhonen, M., Lehtonen, J., Hellen, L., Hirvonen, J. and Yliruusi, J., 2002. Rheological properties of three component creams containing sorbitan monoesters as surfactants. International Journal of Pharmaceutics 247: 103-114.

Komaiko, J.S. and McClements, D.J., 2016. Formation of food-grade nanoemulsions using low-energy preparation methods: A review of available methods. Comprehensive Reviews in Food Science and Food Safety 15: 331-352.

Kumar Dey, T., Ghosh, S., Ghosh, M., Koley, H. and Dhar, P., 2012. Comparative study of gastrointestinal absorption of EPA \& DHA rich fish oil from nano and conventional emulsion formulation in rats. Food Research International 49: 72-79.

Lazzari, M. and Chiantore, O., 1999. Drying and oxidative degradation of linseed oil. Polymer Degradation and Stability 65: 303-313.

Lee, S.J., Choi, S.J., Li, Y., Decker, E.A. and McClements, D.J., 2010. Protein-stabilized nanoemulsions and emulsions: comparison of physicochemical stability, lipid oxidation, and lipase digestibility. Journal of Agricultural and Food Chemistry 59: 415-427.

Lethuaut, L., Métro, F. and Genot, C., 2002. Effect of droplet size on lipid oxidation rates of oil-in-water emulsions stabilized 
by protein. Journal of the American Oil Chemists' Society 79: 425-430.

Lovelyn, C. and Attama, A.A., 2011. Current state of nanoemulsions in drug delivery. Journal of Biomaterials and Nanobiotechnology 2: 626 .

Mahdi Jafari, S., He, Y. and Bhandari, B., 2006. Nano-emulsion production by sonication and microfluidization-a comparison. International Journal of Food Properties 9: 475-485. https://doi. org/10.1080/10942910600596464

Mahdi, E.S., Sakeena, M.H., Abdulkarim, M.F., Abdullah, G.Z., Sattar, M.A. and Noor, A.M., 2011. Effect of surfactant and surfactant blends on pseudo-ternary phase diagram behavior of newly synthesized palm kernel oil esters. Drug Design, Development and Therapy 5: 311.

McClements, D. and Decker, E., 2000. Lipid oxidation in oil-in-water emulsions: impact of molecular environment on chemical reactions in heterogeneous food systems. Journal of Food Science 65: $1270-1282$.

McClements, D.J., 2011. Edible nanoemulsions: fabrication, properties, and functional performance. Soft Matter 7: 2297-2316. https://doi.org/10.1039/c0sm00549e

McClements, D.J. and Rao, J., 2011. Food-grade nanoemulsions: formulation, fabrication, properties, performance, biological fate, and potential toxicity. Critical Reviews in Food Science and Nutrition 51: 285-330.

Micić, D.M., Ostojić, S.B., Simonović, M.B., Krstić, G., Pezo, L.L. and Simonović, B.R., 2015. Kinetics of blackberry and raspberry seed oils oxidation by DSC. Thermochimica Acta 601: $39-44$.

Nakaya, K., Ushio, H., Matsukawa, S., Shimizu, M. and Ohshima, T., 2005. Effects of droplet size on the oxidative stability of oil-inwater emulsions. Lipids 40: 501-507.

Osborn, H.T. and Akoh, C.C., 2004. Effect of emulsifier type, droplet size, and oil concentration on lipid oxidation in structured lipid-based oil-in-water emulsions. Food Chemistry 84: 451-456.

Ostrowska-Ligeza, E., Bekas, W., Kowalska, D., Lobacz, M., Wroniak, M. and Kowalski, B., 2010. Kinetics of commercial olive oil oxidation: dynamic differential scanning calorimetry and Rancimat studies. European Journal of Lipid Science and Technology 112: 268-274.

Pardauil, J.J.R., Souza, L.K.C., Molfetta, F.B.A., Zamian, J.R., Rocha Filho, G.N. and da Costa, C.E.F., 2011. Determination of the Oxidative Stability by DSC of Vegetable Oils from the Amazonian Area. Bioresource Technology 102: 5873-5877. https://doi. org/10.1016/j.biortech.2011.02.022

Peshkovsky, A.S., Peshkovsky, S.L. and Bystryak, S., 2013. Scalable high-power ultrasonic technology for the production of translucent nanoemulsions. Chemical Engineering and Processing: Process Intensification 69: 77-82.

Peterson, J.J., Beecher, G.R., Bhagwat, S.A., Dwyer, J.T., Gebhardt, S.E., Haytowitz, D.B. and Holden, J.M., 2006. Flavanones in grapefruit, lemons, and limes: A compilation and review of the data from the analytical literature. Journal of Food Composition and Analysis 19: S74-S80.

Polychniatou, V. and Tzia, C., 2014. Study of formulation and stability of co-surfactant free water-in-olive oil nano-and submicron emulsions with food grade non-ionic surfactants. Journal of the American Oil Chemists' Society 91: 79-88.

Qi, B., Zhang, Q., Sui, X., Wang, Z., Li, Y. and Jiang, L., 2016. Differential scanning calorimetry study-assessing the influence of composition of vegetable oils on oxidation. Food Chemistry 194: 601-607.

Rao, J. and McClements, D.J., 2011. Food-grade microemulsions, nanoemulsions and emulsions: Fabrication from sucrose monopalmitate \& lemon oil. Food Hydrocolloids 25: 1413-1423. https://doi.org/10.1016/j.foodhyd.2011.02.004

Rudnik, E., Szczucinska, A., Gwardiak, H., Szulc, A. and Winiarska, A., 2001. Comparative studies of oxidative stability of linseed oil. Thermochimica Acta 370: 135-140.

Salvia-Trujillo, L., Verkempinck, S., Zhang, X., Van Loey, A., Grauwet, T. and Hendrickx, M., 2019. Comparative study on lipid digestion and carotenoid bioaccessibility of emulsions, nanoemulsions and vegetable-based in situ emulsions. Food Hydrocolloids 87: $119-128$.

Sajjadi, S., Zerfa, M. and Brooks, B., 2003. Phase inversion in p-xylene/water emulsions with the non-ionic surfactant pair sorbitan monolaurate/polyoxyethylene sorbitan monolaurate (Span 20/Tween 20). Colloids and Surfaces A: Physicochemical and Engineering Aspects 218: 241-254.

Silva, H.D., Cerqueira, M.Â. and Vicente, A.A., 2012. Nanoemulsions for food applications: development and characterization. Food and Bioprocess Technology 5: 854-867.

Solans, C. and Solé, I., 2012. Nano-emulsions: formation by low-energy methods. Current Opinion in Colloid \& Interface Science 17: 246-254.

Sørensen, A.-D.M., Haahr, A.-M., Becker, E.M., Skibsted, L.H., Bergenståhl, B., Nilsson, L. and Jacobsen, C., 2008. Interactions between iron, phenolic compounds, emulsifiers, and $\mathrm{pH}$ in omega-3-enriched oil-in-water emulsions. Journal of Agricultural and Food Chemistry 56: 1740-1750.

Tan, C. and Man, Y., 2002a. Comparative differential scanning calorimetric analysis of vegetable oils: I. Effects of heating rate variation. Phytochemical Analysis 13: 129-141.

Tan, C. and Man, Y.C., 2002b. Recent developments in differential scanning calorimetry for assessing oxidative deterioration of vegetable oils. Trends in Food Science \& Technology 13: 312-318.

Tan, C., Man, Y.C., Selamat, J. and Yusoff, M., 2001. Application of Arrhenius kinetics to evaluate oxidative stability in vegetable oils by isothermal differential scanning calorimetry. Journal of the American Oil Chemists' Society 78: 1133.

Tan, C., Man, Y.C., Selamat, J. and Yusoff, M., 2002. Comparative studies of oxidative stability of edible oils by differential scanning calorimetry and oxidative stability index methods. Food Chemistry 76: 385-389.

Walker, R.M., Decker, E.A. and McClements, D.J., 2015. Physical and oxidative stability of fish oil nanoemulsions produced by spontaneous emulsification: effect of surfactant concentration and particle size. Journal of Food Engineering 164: 10-20.

Waraho, T., McClements, D.J. and Decker, E.A., 2011. Mechanisms of lipid oxidation in food dispersions. Trends in Food Science \& Technology 22: 3-13. 